\title{
MACHADO, Mônica. Antropologia digital e experiências virtuais no Museu de Favela. Curitiba: Appris, 2017. 215 p.
}

\author{
Marina Leitão Damin * \\ *Universidade Federal do Estado do Rio de Janeiro - Rio de Janeiro, RJ, Brasil \\ Doutoranda em Memória Social (bolsista Capes) \\ mldamin@gmail.com \\ https://orcid.org/0000-0002-0037-0445
}


Antropologia digital e experiências virtuais do Museu de Favela, de Mônica Machado, publicada em 2017 pela editora Appris é uma obra que compreende o resultado da pesquisa de pós-doutorado da autora, realizado na University College London (UCL), tendo Daniel Miller, doutor e professor do Anthropology Institute - Department of Material Culture, como supervisor.

A apresentação de Rita Santos, sócia-fundadora do Museu de Favela, faz referência à relevância da pesquisa de longo prazo em forte diálogo com a comunidade local em que trocas de aprendizados se constituíram nas relações cotidianas. As produções colaborativas de plataformas digitais realizadas para o Museu de Favela - hotsite, site, revista digital - em parceria com a universidade se tornaram parte constituinte do legado museológico do Cantagalo, Pavão e Pavãozinho, na cidade do Rio de Janeiro.

O prefácio de Daniel Miller, nomeado "Sharing culture", compara os achados da pesquisa de Machado no Museu de Favela com outra etnografia realizada por Juliano Spyer em uma comunidade pobre na Bahia. Em ambos os casos, argumenta Miller, é possível sugerir que no Brasil o modo de compartilhamento de signos visuais e a interatividade digital são referidas às experiências culturais precedentes, em um ambiente cultural mais receptivo à vida pública e às trocas sociais do que na Inglaterra, onde se observa um movimento de compartilhamento digital mais moderado e discreto.

O livro inicia com um panorama sobre a antropologia digital, refletindo sobre os seus fundamentos como subdisciplina da antropologia no estudo das relações entre tecnologias e humanidades, com ênfase nos sentidos culturais entre as experiências locais e globais, investindo na análise etnográfica dos usos sociais das tecnologias digitais e suas possibilidades de comparações culturais. Em seguida, a argumentação vai na direção de uma profunda e importante contextualização sócio-histórica sobre essas favelas cariocas.

Um rico estudo etnográfico permite ao leitor imergir nas descobertas da pesquisa. Entre as questões analisadas estão o engajamento digital referente ao Museu de Favela, o ativismo e a mobilização nas mídias digitais, as relações sociais por meio dos conteúdos e as interações nas redes sociais, e a presença da espiritualidade e do senso de humor nas narrativas digitais.

A autora discute alguns conceitos existentes no campo da antropologia digital, a exemplo das expressões theory of attainment e polymedia, ainda sem tradução para o português. O conceito de theory of attainment busca refletir 
sobre as experiências digitais como formas de expressão que retém traços de modos de vidas culturais precedentes, não só dos meios de comunicação que antecederam as plataformas digitais como rádio, TV, cinema, mídias impressas, como também as experiências de socialidades que atravessam as histórias das experiências locais das diferentes culturas. Já a noção de polymedia pressupõe a análise dos usos sociais da tecnologia. O conceito se aproxima das noções de mediação, remediação e media ecology, compreendendo os estudos das culturas digitais como vivências de interação, compartilhamento e processos de escolha. A obra apresenta também como contribuição em seu aporte teórico, autores importantes - e pouco traduzidos - da antropologia digital, como Christine Hine (2015), José van Djick (2007, 2013) e o próprio Daniel Miller (2005, 2008, 2010, 2011, 2012, 2016; Miller; Sinanan, 2014, 2017; Miller et al., 2016).

Antropologia digital e experiências virtuais do Museu de Favela resulta em um trabalho de fôlego e relevância, pois é fruto de uma mescla entre a abordagem quantitativa - com a realização de 400 entrevistas com moradores das favelas Pavão, Pavãozinho e Cantagalo - e a qualitativa, apoiada na perspectiva etnográfica e em suas ferramentas (depoimentos, diário de campo, conversas com moradores da favela e referências locais).

Mônica Machado é professora da Escola de Comunicação e do Programa de Pós-Graduação EICOS-IP, ambos da Universidade Federal do Rio de Janeiro (UFRJ), pesquisadora do Programa Avançado de Cultura Contemporânea (PACC/UFRJ) e coordenadora do grupo de pesquisa Coordenação Interdisciplinar de Estudos Contemporâneos (CIEC-ECO/UFRJ).

O livro Antropologia digital e experiências virtuais do Museu de Favela é uma obra de referência no campo emergente da antropologia digital, além de contribuir para a construção da memória das favelas e o registro das histórias de vida de seus moradores e do acervo do Museu de Favela.

\section{Referências}

DIJCK, J. van. Mediated memories in the digital age. Stanford: Stanford University Press, 2007.

DIJCK, J. van. The culture of connectivity: a critical history of social media. Oxford: Oxford University Press, 2013. 
HINE, C. Ethnography for the internet: embedded, embodied and everyday. London: Bloomsbury, 2015.

MILLER, D. Materiality. Durham: Duke University Press, 2005.

MILLER, D. The comfort of things. Cambridge: Polity, 2008.

MILLER, D. Stuff. Cambridge: Polity, 2010.

MILLER, D. Tales from Facebook. Cambridge: Polity, 2011.

MILLER, D. Consumption and its consequences. Cambridge: Polity, 2012.

MILLER, D. Social media in an English village. London: UCL Press, 2016.

MILLER, D.; SINANAN, J. Webcam. Cambridge: Polity, 2014.

MILLER, D.; SINANAN, J. Visualising Facebook: a comparative perspective. London: UCL Press, 2017.

MILLER, D. et al. How the world changed social media. London: UCL Press, 2016. 